\title{
EPISTEMOLOGIAS DA GAMIFICAÇÃO NA EDUCAÇÃO: TEORIAS DE APRENDIZAGEM EM EVIDÊNCIA
}

\author{
Josefa Kelly Cavalcante de Oliveira (UFAL)* \\ https://orcid.org/0000-0002-7320-9011 \\ Fernando Silvio Cavalcante Pimentel (PPGE/UFAL)** \\ https://orcid.org/0000-0002-9180-8691
}

\section{RESUMO}

0 artigo está vinculado à pesquisa Gamificação na Perspectiva dos Multiletramentos, desenvolvida nos anos iniciais do Ensino Fundamental. Tem como objetivo analisar as epistemologias presentes na literatura sobre gamificação. A pesquisa foi realizada com base em revisão sistemática de literatura, conforme os princípios propostos por Yin (2016). O presente trabalho baseou-se no tema de estudo, problema da pesquisa, resumo, palavras-chave, introdução, principais resultados e considerações para análise de dados das dissertações, e como critério de seleção a gamificação na educação. Nesse contexto, as questões epistemológicas são relevantes, na medida em que são elas que estabelecem os critérios que são levados em consideração nas estratégias de gamificação na educação para justificar o caminho proposto para o desenvolvimento da aprendizagem do estudante. Todavia, nem sempre estão alicerçadas em fundamentos que vão além do sendo comum, ou ainda são baseadas em uma perspectiva que contempla a gamificação como ferramenta, instrumento para utilização. Esta pesquisa foi realizada com o apoio financeiro da Coordenação de Aperfeiçoamento de Pessoal de Nível Superior (Capes) no Brasil.

Palavras-chave: Gamificação. Teorias de aprendizagem. Epistemologia.

\section{ABSTRACT}

\section{EPISTEMOLOGIES ISSUES OF GAMIFICATION IN EDUCATION: THEORETICAL PERSPECTIVES IN EVIDENCE}

The article is connected to the Gamification Research in the Perspective of Multiliteracies developed in the Early Years of Elementary School. It aims to analyze the epistemologies present in the literature on gamification. The research based on Systematic Review of Literature, according to the principles proposed 
by Yin (2016). The current work was based on the subject of study, research problem, abstract, keywords, introduction, main results and considerations for data analysis of the dissertations and as criteria of analysis the relationship of gamification with education. In this context, the epistemological issues are relevant, since they establish the criteria that are taken into consideration in the strategies of gamification in education to justify the proposed path for the development of student learning. However, they are not always based on fundamentals that go beyond being common or are still based on a perspective that contemplates gamification as a tool, instrument for use. This research was carried out with the financial support of the Coordination for the Improvement of Higher Education Personnel (Capes) in Brazil.

Keywords: Gamification. Learning theories. Epistemology.

\section{RESUMEN}

\section{EPISTEMOLOGÍAS DE LA GAMIFICACIÓN EM LA EDUCACIÓN: TEORÍAS DE APRENDIZAJE EM PRUEBAS}

El artículo está vinculado a la investigación de Gamificación en la Perspectiva de la Alfabetización múltiple, desarrollada en los primeros años de la escuela primaria. Su objetivo es analizar las epistemologías presentes en la literatura sobre gamificación. La investigación se realizó en base a una revisión sistemática de la literatura, de acuerdo con los principios propuestos por Yin (2016). El presente trabajo se basó en el tema de estudio, problema de investigación, resumen, palabras clave, introducción, principales resultados y consideraciones para el análisis de datos de disertaciones, y como criterio de selección de gamificación en educación. En este contexto, los problemas epistemológicos son relevantes, en la medida en que establecen los criterios que se tienen en cuenta en las estrategias de gamificación en educación para justificar el camino propuesto para el desarrollo del aprendizaje de los estudiantes. Sin embargo, no siempre se basan en fundamentos que van más allá de ser comunes, o aún se basan en una perspectiva que considera la gamificación como una herramienta, un instrumento para su uso. Esta investigación se realizó con el apoyo financiero de la Coordinación para la Mejora del Personal de Educación Superior (Capes) en Brasil.

Palabras clave: Gamificación. Teorías de aprendizaje. Epistemología

\section{Introdução}

0 termo epistemologia é composto por episteme e logos, em grego, ou scientia e ratio, em latim, que originam os vocábulos ciência ou conhecimento e/ou razão e teoria. Significa, portanto, teoria do conhecimento ou da ciência (PAVIANI, 2009). De acordo com Tesser (1995), constitui um campo de estudo da filosofia, a ciência da ciência. De modo geral, a epistemologia pode ser considerada o estudo reflexivo do saber, de como ocorre sua organização, seu modo de funcionamento, seu desenvolvimento e manifestações intelectuais fomentadas. Esse autor menciona que a epistemologia tenta mostrar que a ciência não se organiza 
de forma neutra, mas busca elucidar que todo conhecimento é portador de interesses e de uma dimensão social.

A teoria do conhecimento permite a reflexão e a crítica do conhecimento, ao passo que tenta descortinar as filosofias implícitas nas ciências, apresentando ao cientista a ciência sobre o prisma de um estudo crítico, pois a ciência utilizada sem consciência apresenta pouco rigor científico (TESSER, 1995). A epistemologia, conforme Paviani (2009), busca integrar questões que estão presentes nas decisões metodológicas e esclarece que os processos metodológicos depreendem, de forma consciente ou inconsciente, escolhas epistemológicas. Quer dizer, a epistemologia envolve um conjunto de escolhas, decisões e elaboração de estratégias, da mesma forma a falta do conhecimento epistemológico dificulta a elaboração de pesquisas consideradas adequadas pela comunidade científica. Contudo, ainda se faz necessário a compreensão de que existem diversas tendências epistemológicas (PAVIANI, 2009).

Nesse contexto, as questões epistemológicas são relevantes, na medida em que são elas que estabelecem os critérios que são levados em consideração nas estratégias de gamificação na educação para justificar o caminho proposto para o desenvolvimento da aprendizagem do estudante. Entretanto, nem sempre estão alicerçadas em fundamentos que vão além do senso comum, ou ainda são baseadas em teorias de aprendizagem que contemplam a gamificação como ferramenta, instrumento para utilização, tal qual ocorre com a perspectiva behaviorista que em estratégias de marketing possuem aplicação eficaz, mas que não favorecem o processo de ensino e aprendizagem (FARDO, 2013).

Com base nessas indagações, o objetivo desta pesquisa é fazer uma revisão bibliográfica para identificar quais as teorias de aprendizagem que embasam as estratégias de gamificação e o desenvolvimento de literatura científica sobre gamificação na educação. Por teorias de aprendizagem entende-se, nas palavras de Lakomy (2014), o conjunto de enfoques e perspectivas teóricas, diferentes e complementares, que buscam fundamentar e explicar os elementos que envolvem o processo de ensino e aprendizagem. Esse autor complementa que a interação entre os diversos fatores e elementos que fundamentam as teorias de aprendizagem torna complexo o conceito de aprendizagem, posto que diferem conforme a teoria que a conceitua. Para alguns teóricos a aprendizagem ocorre por meio da repetição, como ocorre com a teoria comportamentalista.

Para os teóricos comportamentais, a aprendizagem pressupõe a mudança de comportamento observável, resultado de reforços externos de recompensas e punições. No prisma cognitivista, por outro lado, os alunos refletem e tomam decisões, interagem com o meio interno e externo, utilizam experiências anteriores, buscam e reorganizam informações para a construção do conhecimento, sendo a aquisição do conhecimento a própria aprendizagem. O sociointeracionismo e o construtivismo são exemplos de teorias cognitivistas (LAKOMY, 2014; SILVA, 2015). Esta pesquisa tem como objetivo analisar as epistemologias presentes na literatura sobre gamificação.

Para alcançar o objetivo, foi realizada uma revisão sistemática de literatura (RSL), tendo como fonte de dados a base de dados da Capes, buscando identificar os elementos epistemológicos presentes nas propostas de gamificação. A questão norteadora desta pesquisa é: quais as perspectivas teóricas encontradas no desenvolvimento de pesquisas cientificas sobre gamificação na educação? Propõe-se uma reflexão entre a gamificação e as perspectivas educacionais mais sistematizadas na Academia, ao passo que se faz necessário compreender as questões epistemológicas estabelecidas academicamente.

0 artigo está estruturado em: primeiramente, uma discussão sobre as questões epistemológicas relacionadas à educação, debatendo algumas definições de teorias de aprendizagem e seu impacto no designer de gamificação; na 
sequência serão apresentadas as concepções sobre gamificação na educação e a descrição da metodologia e dos critérios para o levantamento de dados; por fim, a análise de dados em resultados e discussão e as considerações.

\section{Gamificação e teorias de aprendizagem}

A gamificação no meio educacional parte do pressuposto de agir e pensar como em um game, mas em contexto não game, através da mecânica, dinâmicas e componentes advindos do ato de jogar, como meio para engajar e motivar os indivíduos com o objetivo central de promover a aprendizagem por meio da interação entre as pessoas, com o meio e com as tecnologias (PIMENTEL, 2018).

Conforme Kapp, Blair e Mesch (2014), a gamificação na educação pode ser aplicada de diversas formas, mas há dois tipos predominantes: a estrutural e a de conteúdo. Esses autores apontam que a gamificação estrutural faz uso dos elementos de jogos no processo de aprendizagem com a finalidade de motivar os estudantes a engajarem-se nas atividades propostas por meio de motivações extrínsecas. Nessa perspectiva, baseada em análise comportamental, a estrutura em torno do conteúdo é gamificada, o conteúdo em si não passa por modificação, permanecendo inalterado. 0 intuito é reforçar comportamentos específicos visando atingir os objetivos desejados, como um mecanismo de estímulos e respostas positivas, princípios da teoria de aprendizagem behaviorista.

No panorama da gamificação de conteúdo, ainda segundo Kapp, Blair e Mesch (2014), a gamificação altera parte ou todo o conteúdo de uma aula, curso ou disciplina. Tem como objetivo proporcionar maior interação entre os que fazem parte da estratégia gamificada e o protagonismo por parte dos estudantes, por meio da participação voluntária e objetiva na construção da aprendizagem. Esse tipo de gamificação, em alguns casos, é baseada na teoria da autodeterminação ou faz referência ao construtivismo, contudo as perspectivas de desenvolvimento das estratégias de games variam entre as teorias de aprendizagem e teorias psicológicas, como, por exemplo, a teoria de Flow.

Nesse contexto, Schlemmer (2014) argumenta que a gamificação na educação pode ser estabelecida a partir de duas concepções: sob a ótica interacionista-construtivista, que reflete a educação na cibercultura e contempla elementos como interação e colaboração para motivar e engajar os estudantes em situações de aprendizagem; ou a partir da prospectiva da persuasão, que estimula a competição, cuja perspectiva tem embasamento epistemológico empirista, centrada em elementos como sistema de pontuação, recompensa, premiações.

Por conseguinte, transformar o ato de jogar em mecanismo de estímulo e resposta configura-se, conforme alega Bogost (2011), em uma crítica polêmica à gamificação como uma implementação perversa dos games, confundindo suas propriedades (mecânicas, regras e dinâmicas) com pontos, níveis e recursos primários (como rankeamento, pontuação, classificação), sendo utilizada no marketing para aumentar o número de vendas e envolvendo técnicas repetitivas.

Nesse contexto, até que ponto o uso simplório da gamificação e essa corrupção dos games podem atingir o âmbito educacional? E quais as questões epistemológicas que embasam as estratégias de gamificação na educação?

$\mathrm{Na}$ educação a gamificação apresenta um desenvolvimento mais denso dos elementos de games e possui o intuito de priorizar a aprendizagem a partir de elementos mais complexos, que levem em conta a interação com o meio, com as tecnologias e com as pessoas, o que pode levar a um nível maior de engajamento e motivação nas atividades pedagógicas. 0 Quadro 1 evidencia alguns modelos de teorias de aprendizagem que servem como fundamento para a gamificação na educação. 
Quadro 1 - Teorias epistemológicas que fundamentam a gamificação na educação

\begin{tabular}{|c|c|}
\hline Teoria & $\begin{array}{c}\text { Características da teoria em contexto de } \\
\text { gamificação na educação }\end{array}$ \\
\hline Fluxo (Mihaly Csikszentmihalyi) & $\begin{array}{l}\text { Um sistema adequado ao nível do aprendiz para envol- } \\
\text { vê-lo no estado de fluxo, em constante interesse, no qual } \\
\text { nada mais parece importar, pois a exigência da tarefa é } \\
\text { adequada às habilidades do aprendiz. Desse modo, as } \\
\text { atividades comuns, através da gamificação, recebem } \\
\text { uma nova configuração, um estado de fluxo, o que pode } \\
\text { ser relevante, principalmente aquelas que exigem do } \\
\text { aprendiz perseverança e comprometimento (HAMARI; } \\
\text { KOIVISTO, 2014). }\end{array}$ \\
\hline Condicionamento operante (Skinner) & $\begin{array}{l}\text { Fornece um sistema que visa ao reforço de comporta- } \\
\text { mentos positivos de estímulos à aprendizagem. Por meio } \\
\text { de recompensas ao término de uma determinada tarefa, } \\
\text { ranking com o status dos participantes e feedback para } \\
\text { encorajar o aprendiz a realizar uma determinada ação. É } \\
\text { importante compreender as limitações da análise com- } \\
\text { portamental, uma vez que as recompensas podem vir a } \\
\text { substituir a motivação intrínseca e o ranking deve ter } \\
\text { um equilíbrio entre ganhar e perder, para não desmo- } \\
\text { tivar aqueles que possuem pontuação abaixo da média } \\
\text { (ABDI, 2016). }\end{array}$ \\
\hline $\begin{array}{l}\text { Teoria Motivacional ARCS (Attencion, } \\
\text { Relevance, Confidence, Satisfaction) } \\
\text { (Keller) }\end{array}$ & $\begin{array}{l}\text { A Teoria Motivacional ARCS tem como base elementos } \\
\text { que em conjunto proporcionam as condições considera- } \\
\text { das necessárias para que o aluno possa ser totalmente } \\
\text { motivado pelo processo de aprendizagem. Elementos } \\
\text { como atenção, relevância, confiança e satisfação. } \\
\text { Essa teoria propõe despertar e manter a atenção do alu- } \\
\text { no. Sendo assim, os conteúdos de aprendizagem devem } \\
\text { ser relevantes para que seja significativo aprender o que } \\
\text { é proposto. É necessário promover a confiança do aluno, } \\
\text { para que ele se sinta seguro de realizar todo o processo } \\
\text { de aprendizagem e obtenha satisfação, por meio do sen- } \\
\text { timento de recompensa positiva em torno da aprendiza- } \\
\text { gem (KELLER, 2017). }\end{array}$ \\
\hline Autodeterminação & $\begin{array}{l}\text { Conforme Shi e Cristea (2016), permite aos aprendi- } \\
\text { zes assumir o papel de automotivação na sua própria } \\
\text { educação. As experiências de aprendizagem, para fo- } \\
\text { mentar motivação intrínseca, envolvem três pontos bá- } \\
\text { sicos: a) autonomia, capacidade de regular os próprios } \\
\text { comportamentos e agir conforme suas intenções de } \\
\text { aprendizagem; b) competência, sentimento de alcan- } \\
\text { çar o domínio de habilidades e confiança para viven- } \\
\text { ciar experiencias com maestria; c) ligação, conexão e } \\
\text { interação com os outros. }\end{array}$ \\
\hline
\end{tabular}




\begin{tabular}{|l|l|}
\hline $\begin{array}{l}\text { Aprendizagem Social (Robert } \\
\text { Bandura) }\end{array}$ & $\begin{array}{l}\text { Conforme Kapp (2011), a interação social influencia o } \\
\text { aprendiz a modelar o comportamento para atingir o con- } \\
\text { siderado apropriado e mantê-lo. A interação social com } \\
\text { o ambiente e o comportamento são responsáveis pela } \\
\text { aprendizagem. O aprendiz observa um comportamento, } \\
\text { testemunha seu reforço e o processa internamente. }\end{array}$ \\
\hline $\begin{array}{l}\text { Aprendizagem (apprenticeship) } \\
\text { cognitiva - cognição situada }\end{array}$ & $\begin{array}{l}\text { Fornecer a oportunidade de explorar o ambiente e cená- } \\
\text { rios autênticos com feedback e orientação para realiza- } \\
\text { ção das atividades (KAPP, 2012). }\end{array}$ \\
\hline Design Instrucional & $\begin{array}{l}\text { Segundo Silva (2015), fornece meios de controle do } \\
\text { aprendiz, utilizando materiais, processos e tecnologias } \\
\text { para planejar e implementar soluções que viabilizam a } \\
\text { aprendizagem. Nessa perspectiva, a atenção do aluno } \\
\text { deve ser despertada, os objetivos devem ser claros, fee- } \\
\text { dback constante, primar pelo desempenho e avaliá-lo. }\end{array}$ \\
\hline
\end{tabular}

Fonte: Elaborado pelos autores deste artigo com base em Kapp (2012).

A identificação e observação das teorias e concepções pedagógicas são fundamentais para compreender de que forma a gamificação vem sendo desenvolvida na educação, em virtude do momento histórico e cultural da sociedade, permeada pela cultura digital. Desse modo, o ato educativo visa mais que formar para o trabalho, mas desenvolver a capacidade de colaboração e autonomia e a formação de indivíduos com competência para refletir sobre questões sociais.

\section{Percurso metodológico}

0 presente estudo configura-se como pesquisa qualitativa, que conforme Sampiere, Collado e Lúcio (2013, p. 33), "se baseia mais em uma lógica e em um processo indutivo (explorar e descrever, e depois gerar perspectivas teóricas)". Do mesmo modo, foi realizada com base em Revisão Sistemática de Literatura, conforme os princípios propostos por Yin (2016), que aponta as revisões com o objetivo de reunir o que se conhece sobre um determinado tema, destacando possíveis linhas de pensamento controversas ou díspares, como também o progresso científico que envolveu o tema no perpassar de um período específico determinado pelo pesquisador. É também de cunho descritivo (SAMPIERE; COLLADO; LUCIO, 2013).

Para a pesquisa foi utilizado o catálogo de teses e dissertações da Coordenação de Aperfeiçoamento de Pessoal de Nível Superior (Capes), no intuito de responder à questão de pesquisa que serviu como orientação à revisão sistemática de literatura e para verificar as possíveis evidências epistemológicas/teoria de aprendizagem relacionada à gamificação na educação. Por conseguinte, a questão norteadora é: quais as perspectivas teóricas encontradas no desenvolvimento de pesquisas cientificas sobre gamificação na educação?

Para a realização da RSL foram utilizados os seguintes métodos: a) análise teórico/bibliográfica, para fazer um recorte epistemológico sobre as teorias de aprendizagem no desenvolvimento de pesquisas sobre gamificação na educação; b) levantamento sistemático da literatura - definição da pergunta; c) realização da pesquisa, triagem das dissertações; d) extração de dados e mapeamento; e) síntese dos dados; e f) redação e publicação dos resultados.

Os termos escolhidos para a busca na base de dados foram: gamification, gamificação, gamificação e epistemologia, gamificação e teoria de aprendizagem. A busca foi realizada 
durante o mês de dezembro de 2018. Foram adicionados filtros para que de fato fossem apresentados resultados relevantes para este estudo.

Quadro 2 - Estratégias de busca

\begin{tabular}{|l|l|}
\hline Fonte & Banco de Teses e Dissertações da Capes \\
\hline Área de pesquisa & Ciências humanas \\
\hline Linguagem & Língua portuguesa e inglesa. \\
\hline Período & 2013 a 2018. \\
\hline
\end{tabular}

Fonte: Elaborado pelos autores deste artigo.

Os critérios para seleção das pesquisas foram dissertações de mestrado acadêmico que estivessem relacionadas ao uso de gamificação apenas na área da educação. 0 recorte foi limitado, portanto, à grande área do conhecimento ciências humanas e à área da educação, e refinado para o período dos últimos cinco anos. 0 Quadro 3 apresenta o resultado inicial da busca utilizada para a seleção das dissertações.

Quadro 3 - Resultado das palavras-chave que atendem à pergunta da pesquisa

\begin{tabular}{|c|c|c|c|}
\hline \multirow{2}{*}{ TERMO DE BUSCA } & \multicolumn{3}{|c|}{ CATÁLOGO DE TESES E DISSERTAÇÕES DA CAPES } \\
\cline { 2 - 4 } & SEM FILTRO & COM FILTRO & RELACIONADOS AO TEMA \\
\hline GAMIFICATION & 117 & 11 & 11 \\
\hline GAMIFICAÇÃO & 113 & 13 & 14 \\
\hline
\end{tabular}

Fonte: Elaborado pelos autores deste artigo.

Logo após a busca inicial, das 25 dissertações selecionadas, 10 encontravam-se duplicadas. Todavia duas não estavam disponíveis em rede e por isso não compõem a análise. A dissertação de Cavalcante (2017) analisava os desafios de investigar como as práticas pedagógicas gamificadas podem contribuir para promover a motivação de aprendizado significativo em alunos de cursos de idiomas, a partir da aprendizagem significativa de Ausubel e baseada na Teoria da Autodeterminação; a outra dissertação, de Ferreira (2015), tinha como objeto de estudo a gamificação como estratégia didática na formação de professores. Contudo, não estavam disponíveis em rede para que pudessem compor a análise.

Após a leitura inicial, quatro dissertações foram excluídas por não apresentarem nenhuma relação com a gamificação. A pesquisa de Portal (2016) abordava as estratégias utilizadas pelos diferentes atores envolvidos com educação a distância para minimizar a evasão e potencializar a permanência dos estudantes na modalidade de ensino. A pesquisa de Eufrásio Junior (2015) apresentava um estudo teórico sobre a criação de materiais digitais para curso online na perspectiva do design thinking.

Das duas restantes, a dissertação de Nascimento (2016) baseava-se no desenvolvimento de um jogo para o ensino de ciências e, ainda que mencionasse brevemente a gamificação e apresentasse o termo nas palavras-chave do resumo, não respaldava a pesquisa com base nas estratégias de game, mas na aprendizagem baseada em jogos digitais. A pesquisa de Emilio (2010), por sua vez, mesmo mencionando a gamificação como metodologia ativa, não a tinha como objeto principal de pesquisa, portanto optamos por excluí-la da análise de dados.

As nove dissertações restantes foram consideradas relevantes para a construção desta pesquisa, contribuindo para o embasamento teórico. 0 Quadro 4 apresenta a síntese das dissertações selecionadas. 
Quadro 4 - síntese dos dados apresentados nas dissertações selecionadas

\begin{tabular}{|c|c|c|c|c|}
\hline AUTOR & $\begin{array}{l}\text { Identificação } \\
\text { no artigo }\end{array}$ & Tema & Ano & Palavras-chave \\
\hline Bruno Rezende & D1 & $\begin{array}{l}\text { Gamificação como } \\
\text { prática docente }\end{array}$ & 2018 & $\begin{array}{l}\text { Gamificação; Metodologias } \\
\text { Ativas; Práticas Docentes; } \\
\text { Formação Docente; Ensino e } \\
\text { Aprendizagem. }\end{array}$ \\
\hline Flávio Souza & D2 & $\begin{array}{l}\text { Estratégias e } \\
\text { potencialidades } \\
\text { da gamificação na } \\
\text { educação }\end{array}$ & 2018 & $\begin{array}{l}\text { Educação; Gamificação; } \\
\text { Práticas Pedagógicas. }\end{array}$ \\
\hline Marcelo Fardo & D3 & $\begin{array}{l}\text { Gamificação como } \\
\text { estratégia pedagógica }\end{array}$ & 2013 & $\begin{array}{l}\text { Jogos Eletrônicos; Games; } \\
\text { Gamificação; } \\
\text { Ambientes de } \\
\text { Aprendizagem; Estratégias } \\
\text { Pedagógicas. }\end{array}$ \\
\hline $\begin{array}{l}\text { Mércia } \\
\text { Figueiredo }\end{array}$ & D4 & $\begin{array}{l}\text { Gamificação e } \\
\text { Formação Docente }\end{array}$ & 2016 & $\begin{array}{l}\text { Formação docente; } \\
\text { Gamificação; Formação } \\
\text { continuada. }\end{array}$ \\
\hline Eliane Vicente & D5 & $\begin{array}{l}\text { Apropriações e táticas } \\
\text { dos estudantes na } \\
\text { perspectiva do ensino } \\
\text { com gamificação }\end{array}$ & 2017 & $\begin{array}{l}\text { Apropriação; Estratégia; } \\
\text { Gamificação; Ensino; Tática. }\end{array}$ \\
\hline Fabiana Ribeiro & D6 & $\begin{array}{l}\text { Aprimoramento da } \\
\text { aprendizagem por } \\
\text { meio da gamificação }\end{array}$ & 2018 & $\begin{array}{l}\text { Letramento; Gamificação; } \\
\text { Ensino da Escrita. }\end{array}$ \\
\hline Fábio Alves & D7 & $\begin{array}{l}\text { Gamificadas a partir do } \\
\text { design instrucional }\end{array}$ & 2015 & $\begin{array}{l}\text { Tecnologias da Informação } \\
\text { e Comunicação; Ambientes } \\
\text { Virtuais de Aprendizagem; } \\
\text { Gamificação; Codesign. }\end{array}$ \\
\hline Cristina Martins & D8 & $\begin{array}{l}\text { Gamificação enquanto } \\
\text { práticas pedagógicas }\end{array}$ & 2015 & $\begin{array}{l}\text { Gamificação; Práticas } \\
\text { Pedagógicas; Formação } \\
\text { de Professores; Educação } \\
\text { Continuada. }\end{array}$ \\
\hline Franciele Vieira & D9 & $\begin{array}{l}\text { O ensino de língua } \\
\text { estrangeira com } \\
\text { aplicativos gamificados }\end{array}$ & 2018 & $\begin{array}{l}\text { Estudos culturais em } \\
\text { educação, aplicativos para } \\
\text { celulares, Duolingo, Babbel, } \\
\text { games. }\end{array}$ \\
\hline
\end{tabular}

Fonte: Elaborado pelos autores deste artigo.

0 presente trabalho baseou-se no tema de estudo, problema da pesquisa, resumo, palavras-chave, introdução, principais resultados e considerações para análise de dados das dissertações e como critério para identificar as teorias que envolvem as propostas de gamificação no campo educacional.

Para tanto, como critério serão observados os indícios de teoria de aprendizagem que fundamentam a gamificação na educação (Quadro 1). 
Ressaltamos que a perspectiva epistemológica e, por consequência, a teoria de aprendizagem nem sempre são contempladas de modo consciente pelos pesquisadores. Verificaremos também o tipo de gamificação: estrutural e de conteúdo (KAPP; BLAIR; MESCH, 2014).

\section{Resultados e discussões}

As nove dissertações da base de dados da Capes foram analisadas qualitativamente, com o intuito de verificar as teorias de aprendizagem evidenciadas em cada pesquisa especificamente. Inicialmente, após a leitura das dissertações, foi possível perceber que quatro delas fazem menção ao sociointeracionismo. Por questão de organização do tratamento dos dados coletados, as dissertações serão apresentadas conforme a ordem de classificação do Quadro 4.

A pesquisa de Rezende (2018) aborda a gamificação sob a ótica do professor e sua ação no ambiente escolar. Ainda que faça alusão à teoria de Vygotsky, não há elementos na dissertação e análise de dados que a configure como percussora da pesquisa. Apresenta a gamificação aplicada como metodologia ativa ao fazer docente, como um método "atrativo" para a nova geração conectada. Identifica as metodologias ativas a partir do conceito de Valente e outros (2017), que consideram as metodologias ativas como a criação de situações de aprendizagem para proporcionar aos aprendizes colocar seus conhecimentos em ação, de modo a pensar e conceituar o que aprendem e vivenciam por meio de criação de estratégias cognitivas, da capacidade de refletir sobre suas práticas, construindo conhecimento sobre os conteúdos trabalhados em atividades escolares.

Conforme esse autor, as metodologias ativas possibilitam aos aprendizes interagir com os colegas e professor, explorar atitudes e valores pessoais e sociais e fornecer e receber feedback. A gamificação também é conceituada como metodologia ativa por Filatro e Cavalcanti (2018). Apresenta a gamificação como possibilidade de tornar o ambiente mais interativo e a partir disso enriquecer as práticas pedagógicas dos professores.

O objetivo de Rezende (2018) é discutir criticamente o conhecimento, a adesão, os benefícios e as dificuldades que os docentes do ensino médio à pós-graduação encontram na aplicação da gamificação na educação e esclarece que parte dos professores e docentes desconhecem como desenvolver estratégias de gamificação. Percebe-se uma ênfase maior na motivação extrínseca, o que denota cuidado, uma vez que para Zichermann e Cunningham (2011), enfatizar recompensas extrínsecas pode vir a enfraquecer e destruir as motivações intrínsecas do indivíduo, afetando seu lado motivacional. Nesse sentido, apesar da epistemologia cunhada em Vygostky, o foco é na gamificação estrutural.

Por conseguinte, a pesquisa de Souza (2018), que retrata as estratégias e potencialidades da gamificação na educação, contempla junto ao sociointeracionismo a teoria das Inteligências Múltiplas de Howard Gardner. As principais contribuições de Vygotsky com a teoria da zona de desenvolvimento proximal (ZDP) foram: permitir ao professor conhecer o nível que se encontra o aluno (zona de desenvolvimento real); identificar seu estágio cognitivo; e delimitar o que ele é capaz de atingir (zona de desenvolvimento proximal). Sendo assim, será possível desenvolver estratégias de ensino e aprendizagem na zona de desenvolvimento potencial.

Ressaltam que, para Vygotsky (LAKOMY, 2014), o contexto social influencia diretamente no desenvolvimento cognitivo do indivíduo. $\mathrm{Na}$ pesquisa de Souza (2018), a linguagem e a comunicação caminham juntas ao desenvolvimento cognitivo, posto que a língua é a principal representação cultural e aponta para a mediação como instrumento essencial à aprendizagem por meio da interação social e da representação de signos e símbolos. Os instrumentos constituem mediações, como os signos e a escrita, o que difere o ser humano do comportamento animal, uma vez que os 
animais não criam símbolos e signos como os homens de todas as culturas o fazem.

Souza (2018) respalda sua pesquisa nas implicações propostas pelo sociointeracionismo de modo explícito, ressaltando que cabe à escola conduzir o aluno a construir conhecimento apoiado nos conceitos verdadeiros, nos conceitos científicos, posto que os conceitos verdadeiros sejam delegados à escola para que os alunos realmente aprendam em detrimento dos pseudoconceitos, cujo apoio está nas aparências das coisas e nas experiências pessoais.

Da mesma forma, optam de forma ciente pela Teoria das Inteligências Múltiplas como complemento e integração ao sociointeracionismo. Lakomy (2014) menciona o surgimento de diversas ciências ao longo do percurso histórico da vida humana e menciona a Teoria das Inteligências Múltiplas como forma de rompimento com a concepção de uma inteligência única, igual entre todos os indivíduos e mensurada por testes de Q.I. Cada indivíduo tem capacidades e várias inteligências.

Souza (2018) retrata em seu trabalho as categorias de inteligências propostas por Gardner, que são: a) Linguística; b) Musical; c) Lógico-matemática; d) Espacial; e) Corporal-Cinestésica; f) Pessoal; g) Intrapessoal; e h) Naturalística, sendo as duas últimas acrescentadas após os avanços da pesquisa de Gardner. Dessa maneira, Souza (2018, p. 62) esclarece que as pesquisas "se fundamentam nas proposições epistemológicas de Lev Vygotsky com o intuito de ampliar a compreensão dos estudos acerca da Teoria das Inteligências Múltiplas". Tanto a Teoria das Inteligências Múltiplas quanto o Sociointeracionismo são teorias cognitivas de aprendizagem. A pesquisa de Souza (2018) apresenta indícios de gamificação estrutural.

Dando continuidade, a dissertação de Fardo (2013) - cuja temática é a gamificação como estratégia pedagógica -, para respaldar a gamificação no cenário escolar também utilizou os pressupostos da perspectiva epistemológica de Vygotsky, abordando a gamificação sob o prisma sócio-histórico de Vygotsky, relacio- nando o processo de ensino e aprendizagem com o conceito de Zona de Desenvolvimento Proximal.

0 pesquisador refere-se à gamificação na educação como meio para promover a aprendizagem, ressaltando que os métodos tradicionais de ensino, presentes na maioria das instituições, não são capazes de atender a demanda de formação do indivíduo, que incorpora cada vez as características da cultura digital.

Fardo (2013) traz importantes contribuições acerca do enfoque epistemológico que fundamenta a aplicação da gamificação na educação, ao afirmar que a gamificação na educação deve estar fundamentada na ética profissional e moral para cumprir os objetivos propostos para a aprendizagem e questionando se os aspectos ligados diretamente ao behaviorismo, como uso de recompensas, insígnias, pontos, medalhas e tabelas de líderes, podem de fato ser utilizados na gamificação para potencializar o aspecto interacionista da gamificação e promover aprendizagem.

Para Fardo (2013), o simples fato de acrescentar tais elementos a fim de estimular a motivação para realizar as tarefas torna a gamificação uma abordagem behaviorista de estímulo à mudança de comportamento por meio de recompensas e punições. Aponta também que não existe um caminho único para aplicar a gamificação, já que ela pode ser aplicada com o intuito de direcionar o comportamento do indivíduo, conforme os moldes da teoria comportamental, ou pode ser uma trilha para a construção de experiências significativas, ancorada em uma perspectiva interacionista, ou conforme outra epistemologia que compreenda a aprendizagem e os games de modo mais complexo. A pesquisa de Fardo (2013) tem sua base na gamificação de conteúdo.

Em sequência, outra narrativa que faz crítica ao modelo de gamificação pautado na análise comportamental é a dissertação de Figueiredo (2016), cuja temática é gamificação e formação docente. Esse autor assinala que, partindo do 
princípio behaviorista, a gamificação torna-se um processo de estímulo-resposta-reforço, com o intuito de tornar motivadoras as atividades a serem realizadas. Quer dizer, tarefas são ofertadas, cumpridas ou falhadas, e posteriormente recompensadas. Figueiredo (2016) salienta a importância de um critério analítico que vislumbre que esta influência pode tornase problemática na sua utilização na educação. Propõe o construtivismo como teoria epistemológica contraposta ao behaviorismo, pois, conforme esse autor, o conhecimento é construído e não transmitido; complementa que os estudantes devem possuir um papel ativo no processo de aprendizagem.

A concepção construtivista, como apontado por Lakomy (2014), compreende o processo de ensino e aprendizagem como um processo social de caráter ativo. Contextualizados com o mundo físico e social, os conteúdos constituem produtos sociais e culturais. 0 professor, nessa perspectiva, é um mediador entre o aluno e a sociedade. Todavia, faz menção também aos estudos de Vygotsky sem mencionar as diferenças entre o construtivismo de Jean Piaget e o sociointeracionismo, ambas teorias cognitivas de aprendizagem. Como exemplo dessa diferenciação está a aprendizagem, que para Piaget é condicionada ao desenvolvimento e tem pouca influência sobre o mesmo. Em contrapartida, para Vygotsky a interação social tem influência no desenvolvimento e na aprendizagem, ou seja, quanto mais adquire aprendizagem, maior o desenvolvimento do indivíduo. A pesquisa de Figueiredo (2016) aproxima-se da visão da gamificação sob o prisma da gamificação de conteúdo.

A dissertação seguinte, realizada por Vicente (2017) com o tema "apropriações e táticas dos estudantes na perspectiva do ensino com gamificação", a incidência epistemológica presente na pesquisa é a Teoria da Invenção do Cotidiano proposta por Certeau, cujo estudo pressupõe que a relação social determina o indivíduo e não o contrário, e analisa as práticas sociais cotidianas como processo de interação. Vicente
(2017) justifica a escolha da teoria como uma forma de conceber um espaço de expressão dos estudantes, permitindo que possam criar apropriações e táticas para equilibrar as regras definidas pelo professor - compreendido na pesquisa como agente estratégico - e as necessidades de uso dos estudantes, denominados de agentes táticos.

Para Vicente (2017), a gamificação nesse prisma contribui para reduzir as ações em desacordo com as regras estabelecidas pelo docente, aspecto que a gamificação por si só contempla, pois conforme Busarello (2016) as regras estabelecidas nos games e transpostas em ambientes gamificados têm a função de determinar as ações dos indivíduos para cumprir os desafios e metas estabelecidas e buscam nivelar a complexidade das atividades ao perfil do sujeito, permitindo o desenvolvimento do pensamento estratégico.

Nesse contexto, conforme Busarello (2016), a participação voluntária é um dos princípios dos games que estão presentes na gamificação. É necessária uma interação real entre o sujeito e o jogo e, para tanto, se faz necessário que o indivíduo aceite as metas, regras e o sistema de feedback propostos pelo game e/ou atividade gamificada. Nesse sentido, a perspectiva da gamificação da pesquisa de Vicente (2017) é a estrutural.

A dissertação de Ribeiro (2018) aborda o aprimoramento da escrita por meio da gamificação aplicada pelo viés do letramento. A teoria de aprendizagem que respalda a pesquisa recai sobre Kleiman (2007), que considera que a participação do indivíduo em determinada prática social só é possível quando ele sabe como agir em situações comunicativas, compreende o campo de socialização dos gêneros do discurso e sabe qual e quando usar determinado gênero discursivo.

Outra perspectiva teórica que aparece no relato é a Pedagogia dos Multiletramentos, que difere da ótica de Kleiman (1995), ao passo que o conceito de letramento (múltiplos) faz menção à multiplicidade e variedade de práticas 
letradas e gêneros textuais e de discurso. Os multiletramentos, por sua vez, consideram a multiplicidade cultural e a semiótica de construção dos textos presentes na nossa sociedade (ROJO, 2012). A uma ênfase maior em Kleiman (1995) nos elementos analisados nessa pesquisa. Contudo, em alguns momentos a Aprendizagem Baseada em Jogos Digitais aparecia em maior evidência do que os elementos oriundos dos games. Da mesma forma, o enfoque da gamificação é o estrutural.

A dissertação do pesquisador Alves (2015) apresenta a gamificadas a partir do design instrucional; a aplicação da gamificação é feita no sistema de gerenciamento de aprendizagem Moodle, por meio de dois experimentos envolvendo participantes de graduação em Ciência da Computação e Ciência Tecnológica de Alimentos, e estudantes de pós-graduação na área da Ciência da Computação e administração pública, bem como professores da área de linguística e da educação.

Muitos pesquisadores criticam esse tipo de abordagem, associando-a ao behaviorismo, dado que, para Misukami (1986, p. 8), "esse tipo de ensino volta-se para o que é externo ao aluno: o programa, as disciplinas, o professor. 0 aluno apenas executa prescrições que lhe são fixadas por autoridades superiores". Nesse contexto, o aluno é colocado em uma situação de passividade. 0 enfoque da intervenção é pautado no uso de medalhas, concedidas aos estudantes ao cumprirem uma determinada tarefa. Com forte influência das ideais behavioristas, é apontada por Filatro e Cavalcanti (2018) como estrutural, com pressupostos do behaviorismo.

Por fim, a dissertação de Martins (2015) traz o relato com base na gamificação e formação docente em tempos de cibercultura, retratando as políticas que orientam a organização curricular, como a Lei de Diretrizes e Bases da Educação Nacional, Estatuto da Criança e do Adolescente e documentos oficiais propostos pela Organização das Nações Unidas, UNICEF e Unesco como importantes para a construção de projetos de aprendizagem.

Contudo, propõe um modelo empírico de gamificação pautado nos elementos de Massively Multiplayer Online Role-Playing Game (MMORPG), o qual, de acordo com Achterbosch e outros (2008), tem sua origem no RPG, em que os jogadores vivenciam missões e desafios com distintos objetivos, e difere de um single - player por concentra-se em missões colaborativas com a opção de competir contra outros grupos ou equipes. Conforme esse autor, nos MMORPG as interações sociais entre os jogadores em é um ponto importante, principalmente em um game de interpretação de personagens e na dinâmica de formação dos grupos. Dessa forma, para o sucesso de situações de aprendizagem a partir da gamificação deve-se levar em conta a comunicação e o papel da socialização dentre os que dela participam. A gamificação proposta por Martins (2015) é a de conteúdo.

A dissertação de Vieira (2018) analisa os aplicativos Duolingo e Babel para o ensino de língua estrangeira. Os aplicativos foram projetados com o uso da gamificação, com o incentivo à participação, aos rankings, às pontuações, às metas, aos desafios e à continuidade. Epistemologicamente, a pesquisa de Vieira (2018) apoia-se nos Estudos Culturais, a partir do conceito de cultura da convergência cunhado por Jenkins (2009, p. 27), "na qual as velhas e as novas mídias colidem, na qual a mídia corporativa e a mídia alternativa se cruzam, onde o poder do produtor de mídia e o poder do consumidor interagem de maneiras imprevisíveis". Nesse sentido, traz significativas transformações sobre a forma como os indivíduos interagem com o meio.

Da mesma forma, uma das bases epistemológicas para Vieira (2018) é o M-learning, sendo que para Silva (2015) os embasamentos teóricos para a sustentação desta perspectiva educacional ainda são incipientes, principalmente para a criação de cursos longos e para a realização de avaliação da aprendizagem. Contudo, os dados atuais mostram-se consistentes para indicar que esta perspectiva pode 
contribuir para a aprendizagem nos diversos cenários: formal, não formal e informal. Percebem-se indícios da gamificação sob o prisma estrutural.

Por último, as questões epistemológicas são evidenciadas na literatura sobre gamificação na educação, em sua maioria sem uma discussão sobre sua influência mais densa sobre a gamificação em contexto educacional. As concepções teóricas de aprendizagem em alguns casos assumem um papel ornamental e a gamificação passa a configurar-se como ferramenta motivacional sobre o discurso de inovação para estimular comportamentos positivos sem uma perspectiva mais densa. Em algumas dissertações falta embasamento teórico a respeito da gamificação na educação.

Das dissertações analisadas, cinco apresentam a gamificação estrutural, que compreende a aplicação de elementos de games a um conteúdo já existente (KAPP; BLAIR; MESCH, 2014) e quatro embasam sua pesquisa na gamificação de conteúdo, na qual a dinâmica, a informação e o conteúdo são alterados por meio dos elementos de games (KAPP; BLAIR; MESCH, 2014).

\section{Considerações}

No caminhar da pesquisa, foi observado que há evidência das concepções pedagógicas na literatura científica sobre gamificação na educação, mas que mesmo sendo um tema discutido na área, carece de maior rigor científico para que o embasamento epistemológico não foque no uso da gamificação como uma ferramenta para gerar mudanças positivas de comportamento, mas para que o sentido seja para desenvolver a interação entre as pessoas com as tecnologias e com o meio, com o intuito de promover a construção da aprendizagem. As teorias de aprendizagem evidenciadas no desenvolvimento da gamificação na educação foram: a) sociointeracionismo; b) construtivismo; c) teoria das inteligências múltiplas; d) teoria da invenção do cotidiano; e) prática social de letramento; f) análise comportamental; g) Massively Multiplayer Online Role-Playing Game.

Além disso, foi possível observar a necessidade de conhecer mais profundamente a gamificação, compreender suas mecânicas, componentes e dinâmicas para inseri-la de forma densa e com respaldo teórico preciso, a fim de contrapor a gamificação com enfoque comportamentalista para contribuir com a educação na cultura digital que favoreça a construção de conhecimentos empíricos da gamificação na educação. 0 estudo também permitiu perceber que o embasamento epistemológico é necessário para que a aplicação da gamificação não passe a ser um recurso de adorno para tornar as aulas atrativas e para que as estratégias de games potencializem a construção do conhecimento por meio da colaboração, das missões, descobertas e empoderamento do aluno.

As reflexões levantadas neste ensaio permitem repensar o aperfeiçoamento das pesquisas, possibilitando desenvolvê-las com maior rigor teórico relacionado às teorias que fundamentam a aplicação da gamificação em ambientes educacionais. Longe de significar uma desvalorização das pesquisas cientificas, mas sim reconhecer suas limitações.

Apresentamos aqui os limites da pesquisa que se configura pelo número de dissertações analisadas, mas que abre espaço para novas investigações dos elementos necessários para sua aplicação mais aprofundada. Por fim, foi evidenciado que a principal concepção teórica de aprendizagem que fundamenta a literatura sobre estratégias de games é a Teoria sociointeracionista, mas ainda que em alguns casos apresenta-se um desacordo entre as epistemologias, apontando para paradoxos teóricos.

\section{REFERÊNCIAS}

ABDI, A. Process of gamification: gamifying a tourism concept. 2016. Disponível em: https://www. theseus.fi/bitstream/handle/10024/106171/Abdi_ Amir.pdf?sequence=2. Acesso em: 20 out. 2018. 
ACHTERBOSCH, L. et al. Massively multiplayer online role-playing games: the past, present, and future. 2008. Disponível em: https://www.cs.vu. $\mathrm{nl}$ / eliens/stud/local/cie/a9-achterbosch.pdf. Acesso em: 20 out. 2018.

ALVES, F. P. 0 planejamento de atividades gamificadas a partir de uma abordagem participativa do design instrucional em ambientes virtuais e aprendizagem. 2015.102f. Dissertação (Mestrado em Educação) - Programa de Pós-Graduação em Educação, Universidade Federal de Mato Grosso (UFMT), Cuiabá, 2015.

BOGOST, I. Gamification is bullshit. 2011. Disponível em: https://www.theatlantic.com/ technology/archive/2011/08/gamificationisbullshit/243338/. Acesso em: 20 out. 2018.

BUSARELLO, R. I. Gamification: princípios e estratégias. São Paulo: Pimenta Cultural, 2016.

CAVALCANTE, M. D. L. Gamificação na educação: uma proposta de framework para práticas pedagógicas gamificadas baseada na teoria da autodeterminação. 2017. Dissertação (Mestrado em Educação) - Programa de Pós-Graduação em Educação, Universidade Federal do Oeste do Pará (UFOPA), Santarém, PA, 2017.

EMILIO, T. C. Metodologias ativas no ensino fundamental anos finais e ensino médio: teóricos e estratégias. 2018. 70f. Dissertação (Mestrado em Educação) - Programa de Pós-Graduação em Educação, Universidade do Vale do Itajaí (UNIVALI), Itajaí, SC, 2018.

EUFRÁSIO JUNIOR, N. L. Do design instrucional ao design thinking - desafios e possibilidades para a inovação na educação corporativa na modalidade online: o caso Senacrs. 2015. 123f. Dissertação (Mestrado em Educação) - Programa de PósGraduação em Educação, Universidade do Vale do Rio dos Sinos (UNISINOS), São Leopoldo, RS, 2015.

FARDO, M. L. A gamificação como estratégia pedagógica: estudo de elementos dos games aplicados em processos de ensino e aprendizagem. 2013. 104f. Dissertação (Mestrado em Educação) - Programa de Pós-Graduação em Educação, Universidade de Caxias do Sul (UCS), Caxias do Sul, RS, 2013.

FERREIRA, B. S. 0 uso da gamificação como estratégia didática na capacitação de professores para o uso de softwares educativos. 2015. 94f. Dissertação (Mestrado em Educação) - Programa de Pós-Graduação em Educação, Universidade de
Brasília (UnB), Brasília, DF, 2015.

FIGUEIREDO, M. V. C. Gamificação e formação docente: análise de uma vivência crítico-reflexiva dos professores. 2016. 140f. Dissertação (Mestrado em Educação) - Programa de Pós-Graduação em Educação, Universidade Federal do Ceará (UFC), Fortaleza, 2016.

FILATRO, A; CAVALCANTI, C. Metodologias inov-ativas na educação presencial, a distância e corporativa. São Paulo: Saraiva, 2018.

HAMARI, J.; KOIVISTO, J. Measuring flow in gamification: dispositional flow scale-2. computers in human behavior. 2014. Disponível em: https:// www.researchgate.net/publication/264637700_ Measuring_flow_in_gamification_Dispositional_ Flow_Scale-2. Acesso em: 20 out. 2018.

JENKINS, H. A cultura da convergência. Tradução Suzana Alexandria. 2. ed. São Paulo: Aleph, 2009.

KAPP, K. Bandura's social learning theory. Intelligent fusing learning, technology e business. 2011. Disponível em: http://karlkapp.com/ banduras-social-learning-theory/. Acesso em: 15 set. 2018.

KAPP, K. The gamification of learning and instruction: game-based methods and strategies for training and education. San Francisco: Pfeiffer, 2012.

KAPP, K. M.; BLAIR, L.; MESCH, R. The gamification of learning and instruction fieldbook - ideas into practice. EUA: Wiley, 2014.

KELLER, J. M. Development and use of the ARCS model of instructional design. Department of Educational Research/Florida State University, 2017. Disponível em: https:// yuripavlov.ru/wp-content/uploads/2017/07/ KellerMotivatsiya1987.pdf. Acesso em: 20 out. 2018.

KLEIMAN, A. B. Letramento e suas implicações para o ensino de língua materna. Signo, Santa Cruz do Sul, RS, v. 32, n. 53, p. 1-25, dez. 2007.

KLEIMAN, A. B. (org.). Os significados do letramento: uma nova perspectiva sobre a prática social da escrita. Campinas, SP: Mercado das Letras, 1995. (Coleção Letramento, Educação e Sociedade).

LAKOMY, A. M. Teorias cognitivas de aprendizagem. Curitiba: Intersaberes, 2014.

MARTINS, C. Gamificação nas práticas pedagógicas: um desafio para a formação de professores 
em tempos de cibercultura. 2015.112 f. Dissertação (Mestrado em Educação) - Faculdade de Educação, PUCRS. Porto Alegre, 2015.

MIZUKAMI, M. G. N. Ensino: as abordagens do processo. São Paulo: EPU, 1986.

NASCIMENTO, C. M. O jogo como interface de aprendizagem da ciência no ensino médio. 2016. 99f. Dissertação (Mestrado em Educação) - Programa de Pós-Graduação em Educação, Universidade Tiradentes (UNIT), Aracaju, 2016.

PAVIANI, Jayme. Epistemologia prática: ensino e conhecimento cientifico. Caxias do Sul, RS: Educs, 2009.

PIMENTEL, F. S. C. Conceituando gamificação na educação. 2018. Disponível em: http:// fernandoscpimentel.blogspot.com/2018/. Acesso em: 20 out. 2018.

PORTAL, C. Estratégias para minimizar a evasão e potencializar a permanência em EAD a partir de sistema que utiliza mineração de dados educacionais e learning analytics. 2016. 163f. Dissertação (Mestrado em Educação) - Programa de Pós-Graduação em Educação, Universidade do Vale do Rio dos Sinos (UNISINOS), São Leopoldo, RS, 2016.

REZENDE, B. A. C. Gamificação como prática docente: possibilidades e dificuldades. 2018. 125f. Dissertação (Mestrado em Educação) - Programa de Pós-Graduação em Educação, Universidade do Vale do Sapucaí (UNIVAS), Pouso Alegre, MG, 2018.

RIBEIRO, F. O. A escrita na "Idade Mídia": aprendizagem e aprimoramento por meio da gamificação. 2018. 123f. Dissertação (Mestrado em Educação) - Programa de Pós-Graduação em Educação, Universidade Federal de Alfenas (UNIFAL), Alfenas, MG, 2018.

ROJO, R. Letramentos múltiplos, escola e inclusão social. São Paulo: Parábola Editorial, 2009.

SAMPIERI, R. H.; COLLADO, C. F; LUCIO, M. P. B. Metodologia de pesquisa. 5. ed. Porto Alegre: Penso, 2013.

SCHLEMMER, E. Gamificação em espaços de convivência híbridos e multimodais: design e cognição em discussão. Revista da FAEEBA - Educação e Contemporaneidade, Salvador, v. 23, n. 42, p. 73-89, jul./dez. 2014.

SHI, L.; CRISTEA, A. I. Motivational gamification strategies rooted in selfdetermination theory for social adaptive e-learning. 2016. Disponível em: https://www.dcs.warwick.ac.uk/ acristea/ HTML/ITS16/SL-ITS2016aic.pdf. Acesso em: 20 out. 2018.

SILVA, R. S. Ambientes virtuais e multiplataformas online na EAD. São Paulo: Novatec, 2015.

SOUZA, F. M. G. Gamificação na educação: aproximações, estratégias e potencialidades. 2018. 97f. Dissertação (Mestrado em Educação) - Programa de Pós-Graduação em Educação, Universidade Federal de Ouro Preto (UFOP), Ouro Preto, MG, 2018.

TESSER, G. J. Principais linhas epistemológicas contemporâneas. Educar, Curitiba, n. 10, p. 91-98, 1995.

VALENTE, J. A. et al. Metodologias ativas: das concepções às práticas em distintos níveis de ensino. Revista Diálogo Educacional, Curitiba, v. 17, n. 52, p. 455-478, 2017. Disponível em: http:// dx.doi.org/10.7213/1981-416x.17.052.ds07. Acesso em: 15 out. 2018.

VICENTE, E. M. Apropriações e táticas de estudantes em processo de ensino com gamificação. 2017. 80f. Dissertação (Mestrado em Educação Tecnológica) - Centro Federal de Educação Tecnológica de Minas Gerais (CEFET-MG), Belo Horizonte, 2017.

VIEIRA, F. K. 0 ensino de línguas estrangeiras em aplicativos para telefones celulares: a aprendizagem como um game. 2018. 101f. Dissertação (Mestrado em Educação) - Programa de Pós-Graduação em Educação, Universidade Luterana do Brasil (ULBRA), Canoas, RS, 2018.

YIN, R. Métodos de pesquisa: pesquisa qualitativa do início ao fim. Porto Alegre: Penso, 2016.

ZICHERMANN, G.; CUNNINGHAM, C. Gamification by design: implementing game mechanics in web and mobile apps. Sebastopol: O'Reilly Media, 2011. 